\title{
AS FONTES DA TEORIA QUANTITATIVA DO DINHEIRO NO MANUAL DE CONFESSORES DE FREI RODRIGO DO PORTO (1549)*
}

\author{
ANTON ALEXANDROVICH AFANASYEV**
}

Fecha de recepción: 25 de marzo de 2016

Fecha de aceptación: 10 de junio de 2016

Resumo: Neste ensaio histórico investigamos as origens da Teoria Quantitativa do Dinheiro (Moeda) em Portugal do meio do Século d'Ouro. Temos encontrado as fontes desta teoria na primeira suma portuguesa da teologia moral Manual de Confessores e Penitentes que foi composto pelo franciscano português frade Rodrigo do Porto e foi impressa na Universidade de Coimbra em 1549. Também temos encontrado a inspiração de frei Rodrigo do Porto para a formação do pensamento econômico (das teorias do preço justo e da teoria quantitativa) do grande pensador espanhol e verdadeiro descobridor da Teoria Quantitativa do Dinheiro doutor Martinho de Azpilcueta Navarro.

* Alguns dos resultados deste artigo são apresentados no nosso artigo espanhol sobre a Escola de Salamanca onde há a referencia do manuscrito do presente artigo (Afanasyev, 2016: 17, nota 27). Eu queria agradecer muito os bibliotecários portugueses Sra. Dra. Maria Luisa Ducla Cardia da Biblioteca Nacional de Portugal e Sr. Dr. Antonio Eugenio Maia do Amaral da Biblioteca Geral da Universidade de Coimbra, que me ajudaram muito nesta investigação e me enviaram as cópias das obras de Frei Rodrigo do Porto. Também agradeço muito os organizadores e os participantes do V Simposio Bases L.E. Pensamiento Clásico Español Bases antropológicas de las doctrinas económicas en el siglo XVI que passou sob a direção de professores Sr. Dr. José Ángel García Cuadrado e Sra. Dra. $\mathrm{M}^{\mathrm{a}}$ Idoya Zoroza na Universidade de Navarra (Pamplona, 3 de novembro de 2011). Eu agradeço muito professor Dr. Jesús Huerta de Soto, que me enviou os seus livros sobre a Escola de Salamanca, e professor Dr. Rodrigo Muñoz de Juana, que me enviou o seu livro sobre Martinho de Azpilcueta Navarro.

** Instituto Central de Economia e Matemática da Academia Russa das Ciências (Moscú). Investigador científico (aanton@cemi.rssi.ru). Universidade Nacional de Investigaçao Escola Superior de Economia. Faculdade de Negócios e Administraçao. Professor da Cátedra de Analítica de Negócios. 
Abstract: In this historic essay we have investigated the origins of the Quantity Theory of Money in Portugal the middle of the Golden Age. We have found out the origins of this theory in the first Portuguese book of moral theology Manual de Confessores e Penitentes that was composed by the Franciscan Portuguese friar Rodrigo do Porto and was printed in the University of Coimbra in 1549. Also we have found out the inspiration from father Rodrigo do Porto for the formation of economic thought (the theories of just price and the quantity theory) of the great Spanish thinker and true discoverer of the Quantity Theory doctor Martinho de Azpilcueta Navarro.

Palavras-chave: Teoria Quantitativa do Dinheiro (Moeda), Século d'Ouro, Manual de Confessores (1549), Rodrigo do Porto, Martim de Azpilcueta Navarro

Keywords: Quantity Theory of Money, Golden Age, Manual de Confessores (1549), Rodrigo do Porto, Martinho de Azpilcueta Navarro

\section{I \\ INTRODUÇÃO}

A Teoria Quntitativa do Dinheiro é a teoria básica da ciência econômica. Esta teoria afirma que o valor do dinheiro (em referencia à produtos e outro dinheiro) é determinada principalmente pela sua quantidade e muda-se [ceteris paribus] na proporção inversa à sua quantidade. ${ }^{1}$

Como manteve Marjorie Grice-Hutchinson, Baronesa von Schlippenbach (1909-2003) no seu livro The School of Salamanca (1952), a Teoria Quantitativa do Dinheiro foi descoberta pelo lente da Cátedra de Prima de Cânones nas Universidades de Salamanca e Coimbra, muito famoso, ilustre e venerável doutor espahnol Dr. Martinho de Azpilcueta Navarro (1492-1586) no seu Comentário resolutorio de Cambios escrito com outros quarto como a adição do seu Manual de Confessores e Penitentes no ano de 1556 (Grice-Hutchinson, 1952: 52).

${ }^{1}$ Veja-se, por exemplo, o tratamento da teoria quantitativa nos livros didáticos modernos da macroeconomia: N. Gregory Mankiw.Principles of Macroeconomics. 7th edition. 2015. Page 349. e Roger A. Arnold. Economics. 12th edition. 2014. Pages 353356. 
Enquanto isso, o autor da primeira edição do Manual de confessores e penitentes (1549) (Ilustração 1) era um amigo anônimo de Azpilcueta, um religioso da Ordem de São Francisco da Seráfica Província da Piedade. Muito provavelmente este autor era Frei Rodrigo do Porto. Portanto, é muito importante para investigar as duas coisas seguintes: 1) a contribuição de Frei Rodrigo do Porto para a Teoria Quantitativa do Dinheiro e 2) a inspiração possível de frade Rodrigo do Porto para a formação do pensamento econômico de Martinho de Azpilcueta, especialmente da sua Teoria Quantitativa da Moeda.

II

\section{A BIOGRAFIA DE FREI RODRIGO DO PORTO}

Em primeiro lugar, temos que investigar a biografia de Rodrigo do Porto. Sabemos muito pouco a sua vida e não sabemos as datas exatas do seu nascimento e da sua morte. Diogo Barbosa Machado (1682-1772), o abade da igreja paroquial de San Adrian Sever e membro da Real Academia Portuguesa, escritor e bibliógrafo português, na sua Bibliotheca Lusitana, Historia, Critica e Chronologica nos informou: «Fr. Rodrigo do Porto, cujo apellido denota o lugar que lhe deo o berço, religioso da Serrafica Provincia da Piedade, e dos primeiros professores de taõ austero instituto, sendo Secretario no Capitulo celebrado em Borba a 8 de Setembro de 1514» (Barbosa Machado, 1752: 654). ${ }^{2}$

Então podemos assumir que Rodrido do Porto nasceu no último trimestre do século XV e provavelmente foi contemporâneo da

\footnotetext{
${ }^{2}$ Frei António Pereira da Silva, OFM (1931-2012) escreve: «Sobre a paternidade do Manual, informa Barbosa Machado que o autor é Fr. Rodrigo do Porto, franciscano da Província da Piedade, natural, como o apelido sugere, da cidade do Porto. Viveu nos séculos $\mathrm{XV}$-XVI, desconhecendo-se as datas precisas de seu nascimento e morte. Acrescenta Barbosa Machado que Fr. Rodrigo foi dos primeiros professos de sua Província e participou como secretário no capítulo custodiai (nesta altura a fundação reformista de Fr. João de Guadalupe era ainda apenas Custódia) celebrado em Borba a 8 de Setembro de 1514. Versado em teologia moral, publicou, sob anonimato, "a primeira suma de moral que saiu em língua vulgar neste Reino, merecendo repetidos elogios do grande Doutor Martin Azpilcueta Navarro, oráculo da jurisprudência canónica"» (Pereira da Silva, 1975: 369).
} 
primeira geração da Escola de Salamanca e da mesma idade (ou um pouco mais velho) como foram Francisco de Vitoria, Domingo de Soto, Martinho de Azpilcueta, Juan de Medina.

Sobre a data da sua morte sabemos só que Fr. Rodrigo faleceu entre 1552 e 1567. Em 1552 Fr. Rodrigo trabalhava com o Doutor Navarro sobre a segunda edição do Manual de Confessores ${ }^{3}$. No primeiro compêndio português do Manual de Fr. Rodrigo Compendio e sumario de confessores tirado de toda a substancia do Manual (1567) o ministro provincial do Convento da Piedade ${ }^{4}$, Frei Masseu de Elvas (?-1574), que foi responsável pela edição deste Compendio português na sua dedicatória ao Cardeal Infante Dom Henrique, inquisitor-mór destes reinos, escreve: «Hum religioso da qual mouido com sancto zello das almas, por cujo amor o filho de Deos se deu empreço \& redempção copilou a substancia do Manual de Confessores, pera mais manualmente ser vsado \& tractado dos menos doctos, porque os mais sabios podem yr beber as fontes donde manão estes Regatos. Fallecendo este Religioso da vida presente, foyme mandado per obediencia de meus superiores que tirasse a luz, \& fezesse Imprimir este Compendio por parecer que seraa proueytoso ao stado ecclesiastico.» (Rodrigo do Porto, 1567: A iij).

${ }^{3} \mathrm{O}$ doutor Martinho de Azpilcueta Navarro escreve no prologo introductorio à segunda edicão portugesa do Manual de Confessores e penitentes (1552): «Como lo [=o Manual] comence a reueer tercera vez, haura ya quasi dos años, a ruego de los mismos [=autor e outros], para effecto de se imprimir otra vez: nos parescio, q se podia muy mucho mejorar, para mejor merescer el dicho testimonio enel estilo, allegaciones, sentencias, y resoluciones, si muchas cosas embueltas y obscuras se desemboluiessen, y declarassen, y muchas se quitassen, mudassen, y añadissen: con tanto estúdio, cuydado, y tiẽto, quãto tã infinita, y varia difficultad, subtilidad, y utilidad requeria. $Y$ comunicado esto cõ sus paternidades, y cõsyderado, ̃̃ por algunos respectos no conuenia, ̃̃ esto se hiziesse en su solo nõbre, ni enel solo mio, ni que se distinguiesse lo del uno delo del otro. Acordamos, q̃ por la charidad Christiana, que principalmente busca la gloria de Jesu Christo, el me comunicasse los trabajos, q̃ puso en cõponerlo: y yo a el los q̃ pornia (sic) por mi parte en reformarlo, y quedasse comun de ambos y hablassemos en el juntos, sin dezir esto puso el uno, y aquello anadio, quito, o mudo el otro, conformandonos en todo, y q dando vnanimes, como es vno el espiritu, q hemos desseado.» Rodrigo do Porto, Martin de Azpilcueta (1552), Al pio lector, el doctor Martin de Azpilcueta Nauarro, Salud. Citamos por Pereira da Silva, A. (1975), pp. 372373.

${ }^{4}$ Sobre Fr. Masseu de Elvas veja-se (Monforte, 1751: 453). 
III

\section{A AUTORIA DA PRIMEIRA EDIÇÃO \\ DO MANUAL DE CONFESSORES (1549)}

A autoria da primeira edição do Manual de Confessores com grande probabilidade é atribuída a Frei Rodrigo do Porto. Na sua Bibliotheca Lusitana, Historia, Critica e Chronologica $(1741,1752)$ o abade Barbosa nos informa: «[Fr. Rodrigo do Porto] Foy ornado de singulares virtudes, e profundamente instruido na Teologia Moral publicando sem o seu nome a obra seguinte que foy a primeira summa de Moral, que sahio em lingoa vulgar neste Reino merecendo respeitos elogios do grande Doutor Martinho de Azpilcuela Navarro Oraculo da Jurisprudencia Canonica, em cuja obra depois trabalhou Fr. Antonio de Azurara da mesma Provincia do qual se fez mençaõ em seu lugar.» (Barbosa Machado, 1752: 654). O abade também confirma: «...Manual de Confessores, e penitentes, composto (como querem muitos) por Fr. Rodrigo do Porto Religioso de seu Instituto, mas concorrendo com grande copia de doutrinas canonicas, e moraes para o mesmo Manual quando sahio illustrado pela doutissima penna do insigne Doutor Martinho de Azpilcuela Navarro, cujo grande socorro confessou ter recibido na Dedicatoria ao Cardial D. Henrique do dito Manual impresso em Coimbra por Joaõ de Barreira, e Joaõ de Alvres 1552.» (Barbosa Machado, 1741: 213).

O Doutor Martinho de Azpilcueta Navarro explicou ao cristão leitor que o autor do Manual pela sua humildade não quisera nomear-se: «Por tres respectos principalmente Christiano lector, dire sin saberlo autor desta obra lo que me parece. ... El postero por temer que como el autor su humilidad no quiere nõbrarse: se terma por apocripha, baxa y vna de por ay, con que su gran fructo se impidiesse.» (Rodrigo do Porto, 1549: El doctor Martín de Azpilcueta Navaro al lector, Ai.) Frei António Pereira da Silva esclarece: "A "altíssima humildad" celebrada por Navarro era, de facto, apanágio não somente do autor mas também de sua família religiosa: a província franciscana da Piedade. Na austeridade geral professada e na humildade individual de seus membros se filiava o costume, pouco simpático para os investigadores, de os religiosos da mencionada província franciscana, vulgarmente 
conhecidos por capuchos, exercerem o apostolado da palavra escrita sob anonimato pessoal, limitando-se a indicar o nome do instituto, medida que bastava e era outrossim necessária para garantir a responsabilidade eclesiástica e civil das publicações e o

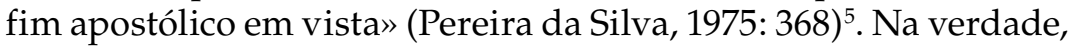
sabemos mais exemplos de tal humildade e tal austeridade dos religiosos franciscanos. No ano de 1549 em Coimbra foi impresso o livro Preparaçam spiritual de catholicos composto também por um anônimo religioso da ordem de São Francisco da Provincia da Piedade. Além disso, em 1567 sob as ordens do Cardeal Infante Dom Henrique foi publicado acima mencionado Compendio e sumario de confessores tirado de toda a substancia do Manual composto por um anônimo frade menor da ordem de São Francisco da mesma provincia da Piedade. Segundo os autores do Diccionario Da Lingoa Portugueza $(1793)^{6}$, este frade menor era Frei Antonio de Azurara que ajudava a Fr. Rodrigo do Porto e Dr. Martinho de Azpilcueta Navarro nos seus trabalhos sobre a segunda edição portuguesa do Manual de Confessores (1552) e depois trabalhou com Dr. Navarro sobre a edição espanhola deste Manual (1556) ${ }^{7}$.

5 «Somos informados na Crónica da Província da Piedade: "Somente de escritores de livros [a Província da Piedade] tem lançado poucos; porque, como nela não havia estudo de letras adquisitas, faltavam-lhe os meios para os ter; contudo, ainda assim, passam de doze [os autores], como se pode ver na Bibliotheca Lusitana [de Barbosa Machado]; se bem que os mais destes, por sua humildade, calaram seus nomes, quando deram à estampa." Entretanto, é muito natural que o nome do autor fosse conhecido não só dentro como fora da equipa responsabilizada pelas edições do Manual. Terá mesmo sido transmitido à posteridade em fontes escritas contemporâneas. Infelizmente, porém, as fontes bibliográficas dos séculos XVI e XVII são raras e parcas em informações criteriosas. Mais escassas são ainda as fontes, e sóbrias as informações, quando se trata de individualidades franciscanas dos ramos mais austeros. Das fontes bibliográficas que tivemos à mão, a primeira em que encontramos nominalmente identificado o autor do Manual de confessores e penitentes data da primeira metade do século xvin: a Biblioteca Lusitana de Barbosa Machado. Sabemos, porém, que este conheceu fontes franciscanas anteriores, nas quais recolheu os dados biobibliográficos que transmite.» (Pereira da Silva 1975: 368-369). Sobre Fr. Rodrigo do Porto e a autoria do Manual de Confessores veja-se também (Barbosa Machado, Sousa Farinha, 1786: 78; Barbosa Machado, Sousa Farinha, 1787: 302; Rebello da Costa, 1789: 348; Costa de Macedo, 1799: 143).

${ }^{6}$ Veja-se (Diccionario, 1793, tomo I: xcii).

${ }^{7}$ Veja-se (Rodrigo do Porto, Azpilcueta Navarro, M. de, 1556: Al pio Lector, el Doctor Martin de Azpilcueta Nauarro, Salud). 
O Doutor Navarro escreve que o franciscano português terminou os seus trabalhos sobre o Manual no ano de 1547 e, em seguida, o Cardeal Infante Dom Henrique mandou Azpilcueta rever o manuscrito do trabalho antes de imprimir dois anos depois: «Lo otro, porque. V.A. fue la causa, de que entiendesse en cosa tan pia: por me hauer mandado cinco años ha, que reuisse el dicho Manual antes $\tilde{\mathrm{q}}$ se impimiesse, para vn effecto: Lo qual causo que despues de impesso, à ruego del mismo autor, y otros lo remirasse para otro: de que resulto esta tercera reuista tan larga, y tan trabajosa.» (Rodrigo do Porto, Martin de Azpilcueta, 1552: Ai).

27 de julho de 1549 Manual de confessores e penitentes, que tinha sido escrito por Fr. Rodrigo do Porto «a lounor \& gloria de nosso senhor Iesu Christo e sua gloriosa madre», foi impresso na «muyto nobre e leal cidade» de Coimbra pelos imprimidores da mesma universidade João de Barreira e João de Alvares.

IV

A TEORIA QUANTITATIVA DO DINHEIRO ANTES DO MANUAL DE CONFESSORES

Poucos antecessores de Fr. Rodrigo do Porto e Martinho de Azpilcueta incluíram o dinheiro a suas doutrinas do preço justo e indicaram uma relação direta entre a quantidade de dinheiro e os preços dos bens. Entre eles eram o grande doutor Nicolaus Copérnicus (1473-1543), e Tommaso de Vio, o famoso Cardeal Caetano (14691534), e um anônimo doutor Saravia de la Calle Veronense, o autor de Instruccion de mercaderes muy provechosa (1544) e, até certo ponto, o grande historiador e humanista português dom Damião de Goes (1502-1574).

No seu primeiro manuscrito dedicado aos problemas monetários Tractatus de Monetis (1519) Copernicus indicou que "vilior etiam redditur moneta ad ejus copiam» (Copernicus, 1924: 1; Afanasyev, 2000: 64). Mais tarde no seu outro manuscrito Monete cudende ratio (1526) Copernicus escreveu: «Vilescit hec ut plurimum propter nimiam multitudinem, utpote si tanta argenti copia in monetam transierit quoadusque argenti massa ab hominibus magis quam moneta desideretur: perit nempe hoc modo dignitas monete, 
quando per ipsam tantum argenti non licet emere quantum ipsa pecunia continet, sentiaturque major profectus eliquando argentum in monete destructionem, cujus remedium est non amplius monetam cudere donec se ipsam coequaverit, reddaturque carior argento. ... Hinc illa vulgaris et perpetua querimonia aurum, argentum, annonam, familie mercedem, opificum operam et quidquid in humanis usibus est solitum, transcendere precium; sed oscitantes non expendimus omnium rerum charitatem ex vilitate monete provenire. Crescunt enim ac decrescunt etiam ad monete conditionem: presertim aurum et argentum que non ere vel cupro, sed auro et argento, appreciamus.» ${ }^{8}$ (Copernicus, 1864: 52, 62).

O Cardeal Caetano no seu livro In secundam secunde sanctissimi ac preclarissimi doctoris Thome Aquinatis ordinis Predicatorum Cõmentaria celeberrima (1519) explica que o preço da pérola cai quando não há compradores e os preços das outras coisas caem, se há falta de dinheiro?.

O doutor Saravia de la Calle, por seu lado, recorda o dinheiro entre os fatores que determinam o preço justo. Ele escreve: «Iusto precio de la cofa es aquel que comunmente corre enel lugar: \& tiempo del contracto: al contado: confideradas las particulares circunftancias de la manera del vender \& comprar: \& la abundancia de las mercaderías, la adundancia del dinero, la muchedumbre

${ }^{8}$ Tradução em francês: «La monnaie perd surtout de sa valeur quand on l'a trop multipliée, lorsque, par exemple, une si grande quantité d'argent a été transformée en monnaie, que les hommes en arrivent à rechercher l'argent en lingot plus que le numéraire. La monnaie perd toute sa dignité, quand elle ne peut plus acheter autant d'argent qu'elle en contient et qu'il y a profit à la refondre. L'unique remède alors, c'est de ne plus frapper de monnaie jusqu'à ce qu'elle ait repris son équilibre et qu'elle ait reconquis une valeur plus élevée que celle de l'argent. ... De là vient cette plainte incessante qui retentit de tout côté, que l'or et l'argent, le blé et les provisions domestiques et le travail des artisans, tout ce dont les hommes font usage d'ordinaire, augmente de prix. Notre négligence nous empêche de voir que la cherté de toutes choses provient de l'avilissement du numéraire. En effet, leur prix augmente et diminue proportionnellement à la monnaie, surtout celui des métaux précieux, que nous estimons, non en airain ou en cuivre, mais en or et en argent.» (Copernicus, 1864: $53,63)$.

9 «Un' gẽme qũ nõ habent emptores: viliffime vẽdũtur. ... Et fimile videmus in alijs rebus q' qn' ĩ aliq' loco vel tempore nõ ĩdigẽt: aut nõ vtũtur rebus aliquibus neq'ũt illas emere $\mathrm{p}^{\prime} \mathrm{p}^{\prime}$ penuriã pecunie, vilefcũt res hujusmodi notabiliter» (De Vio, 1519: In articulo 1 q. 77 , f. cliii). 
delos compradores \& vendedores \& el aparejo que ay para auer las tales cofas \& el prouecho que ay del vso de ellas a arbitrio de buen varon, excluydo todo engaño \& malicia" (Saravia de la Calle Beronense, 1547: Instrucion de los tratos del comprar \& vender, cap. 2, ff. xvi-xvii).

O doutor Saravia também confirma que as coisas encarecem quando há abundância de dinheiro: «...fola la abundancia de mercaderes \& dinero haze fubir el precio dela cofa, como leemos que la abundancia de dineros y riquezas que Otauiano augusto truxo a roma, fueron caufa que las cofas valieffen al doblo que primero» (Saravia de la Calle Beronense, 1547: Instrucion de los tratos del comprar \& vender, cap. 2, f. xviii).

As idéias de Damião de Goes eram em algum sentido semelhantes às idéias de Copérnico. Dom Damião de Goes na sua Carta a D. João III por causa cuhnagem da moeda (entre 1544 e 1549) escreveu $^{10}$ : «Dizem sõr que quer V.A. aguora de novo mãdar [qunhar] moeda, $\mathrm{q}$ he cousa em $\mathrm{q}$ hos reis cuidam sempre [em seu] proveito, mas sai lhes $\mathrm{m}^{\text {tas }}$ vezes hao contrairo [perque a] novidade das moedas he mais dapnosa e peiuizo [destes] Reinos q ha guerra porque desta saem $m$. ${ }^{\text {tas }}$ vezes ... e, amizades e da outra se segue ha carestia de mantim. ${ }^{\text {tos }}$ e fructos da terra e asy das mercadorias naturaes como estrangeiras, ha qual carestia... vez faz pee mingua he mais de todo dessarreigua» (Baião, 1919: 33).

Enquanto isso, até o ano de 1549 muitos outros teólogos e juristas não incluíram a quantidade de dinheiro nas suas doutrinas de preço justo. Eles seguiram a doutrina de São Tomás na qual o valor do dinheiro em referencia aos bens deve ser fixado pela lei (Thoma Aquinatis, Ptolomaeus de Lucca 1509, Liber II, cap. XIII, f. LVII-LVIII; De Vio 1506, cap. 7, ff. 52-54; Muñoz de Juana, 1998: 328329).

${ }^{10}$ Veja-se (Cardoso, 2001: 150). 


\section{$\mathrm{V}$ \\ A TEORIA QUANTITATIVA DO DINHEIRO \\ NO MANUAL DE CONFESSORES (1549)}

Muito importante contribuição de Fr. Rodrigo do Porto para a formação da Teoria Quantitativa do Dinheiro é que, na sua opinião (Ilustração 2), os principais fatores que determinam o preço justo de uma mercadoria são a sua oferta e a quantidade de dinheiro com que se compra ${ }^{11}$ : «Pera declaraçã das cousas ditas atras, em esta materia de comprar \& vender, he de notar que ho preço conuem que seja conforme ao valor da cousa que se vende ou compra, a qual nam estaa sempre em hũ ser mas mudasse, segundo os tempos, \& a pouquidade ou abondãça daquella mercadoria \& do dinheyro com que se ha de comprar como parece nos tempos de esterelidade, ou fortuna ou đ mortes. E por tanto quando o preço he taxado, polos que gouernan a cidade, \& lugar, esse ha de guardar sem falta.» (Rodrigo do Porto, 1549: cap. XXIII Dos peccados mortaes, p. 393).

Aqui encontramos o enfoque macroeconômico de Fr. Rodrigo do Porto para a formação de preços —os preços absolutos ou nominais que representam os bens em termos monetários e o valor ou o nivel desses preços depende da quantidade de dinheiro no país.

Além disso, esses dois fatores acima mencionados - a quantidade de dinheiro e a quantidade das mercadorias - eram as principais causas do encarecimento geral na Península Ibérica no meio do século XVI. De fato, muito ouro e muito prata foram trazidos das Indias para a Espanha e muitas coisas vendáveles haviam exportado da Espanha para o Novo Mundo.

A primeira causa do encarecimento - a abundância de dinheiro- foi evidente inicialmente no Novo Mundo em 1549 depois o descobrimento das minas de Potosí, no Vice-Reino do Peru (Popescu, 1984). Sobre isso escreveram o presidente da Real Audiência de Lima «pai dos povos, pacificador e salvador do Peru» dom Pedro de La Gasca ${ }^{12}$ em 1549, o seu soldado-cronista Pedro de Cieza

${ }^{11}$ Veja-se (Afanasyev, 2004: 44-45) e (Afanasyev, 2013: 61-62).

12 «El salario que se da á los oidores es tan poco para poderse sustentar en esta tierra, que por la cuenta que á Dios debo, tengo duda que se pueda sustentar la mitad 


\section{de León ${ }^{13}$ em 1553, o terceiro vice-rei do Peru dom Andres Hurtado de Mendoza, o segundo Marquês de Cañete ${ }^{14}$ em 1556 (Popescu, 1984). Um pouco mais tarde esta causa do encarecimento geral foi evidente na Península Ibérica de que nos informaram o grande pensador espanhol Frei Bartolomé de Las Casas ${ }^{15}$ em 1552, o histo- riador Francisco López de Gómara ${ }^{16}$ em 1556-1558 (Popescu, 1984)}

del año con ello, á lo menos en este tiempo que tan falta ha quedado esta tierra con las desventuras pasadas de las cosas necesarias para vivir, que no se compra con un peso de oro lo que en España se puede comprar con un real» (Levillier, 1921: 138). «En estos dias se me escribieron muchas cartas de minas de plata que en diversas partes se habían descubierto, y que mostraban ser ricas, y en especial en los términos de Guamanga se habían hallado en dos partes, y que en los del Cuzco se habían hallado en el Collao. Espérase tan gran groseza en esta tierra que la plata valga tan poco, que se tenga por cosa no creedera, porque aun ahora lo es á los que no lo véen. Y aunque sea cosa de menudencias no dejaré de hacer relación aquí dellas para que V. S. mejor entienda la groseza desta tierra por lo poco que en ella valen los dineros» (Levillier, 1921: 181). «...Me paresce lo que antes que se les deue de doblar el salario, porque ávn cada dia cresce la carestía desta tierra, como va cresciendo la riqueza della» (Levillier, 1921: 214).

13 «Las estancias y heredamientos tienen en este tiempo gran precio, causado por la riqueza que se ha descubierto de las minas de Potosí» (Cieça de Leon, 1553: cap. CVII, f. cxxi).

14 «Yo he tomado aqui a cuenta del salario que vuestra magestad me manda dar diez y siete mil y trezientos y tantos pesos que he avido menester para mi aviamiento que no se pueden pensar los gastos de aca que solo de pasar mi casa desde nonbre de dios aqui me cuesta mas de diez mil pesos porque como la tierra es tan gruessa vale el dinero muy poco» (Levillier, 1921: 264).

15 «...y aun estos reynos de Castilla los açota Dios cada dia, y hay grã temor no los assuele por los grandes peccados que la gente Española ha cometido en las indias: de lo cual vemos vn manifiesto castigo que todo el mũdo lo vee y dice por essas calles con que Dios nos aflige y muestra auer sido muy offendido de nosotros en aquellas partes por la destruycion de aquellas naciones: y es que de tan infinitos thesoros como dellas a estas se han traydo, que nunca el rey Salomon ni otro rey del mũdo tanto oro ni plata poseyo, ni vio, ni oyo: no aya quedado en estos reynos ninguno: y aun delo que en España auia puesto: que era poco antes que las indias se descubriessen: tampoco parece meaja. Por lo qual todas las cosas valẽ tres doblado precio que valer solían. Y por esta causa la gente pobre padesce grãdes miserias y necessidades: y a vuestra magestad que tan bien emplea su vida en augmento de la fe catholica redunda dello gran necessidad et impossibilidad de hazer grandes hazañas en seruicio de nuestro todo poderoso Dios: como verdaderamente pudiera hazer si tan grandes desordones por la dicha dañada encomiẽda y lo que a ella precede que son las injustas guerras no ouiera sucedido en las indias...» (Las Casas, 1552: razon 10). Veja-se também (Popescu, 1984: 33-34).

${ }^{16}$ «Ay empero gran diferencia de aquel tiempo a este en muchas cosas, como es en el trage, gasto, y precio de cosas, a causa, segun mi juizio, de la mucha plata y oro que 
e, é claro, o oráculo de jurisprudência canônica, o famoso Dr. Martinho Azpilcueta Navarro em 1556 (Grice-Hutchinson, 1952: 52).

Portanto, no período 1549-1556 a relação direta entre a quantidade do dinheiro e os preços dos bens ficou claro para as pessoas practicas, mas muitos professores passaram a considerar que o valor do dinheiro em referencia aos bens foi determinada pela lei e que não era justo vender o dinheiro de mais ou menos da taxa fixada pela lei. Este problema foi resolvido pelo doutor Martinho de Azpilcueta Navarro em 1556.

\section{VI \\ O CONTRIBUIÇÃO DE FR. RODRIGO DO PORTO PARA A FORMAÇÃO DO PENSAMENTO ECONÔMICO DE MARTINHO DE AZPILCUETA}

Três anos após a primeira impressa do Manual de Confessores a doutrina do preço justo de Frei Rodrigo do Porto estava incluída na segunda edição deste Manual (1552), que já foi composto pelos dois autores: Frei Rodrigo e Doutor Navarro ${ }^{17}$. Na verdade, Frei Rodrigo e Doutor Navarro repetiram a doutrina do preço justo de Frei Rodrigo com a adição de lugar e maneira de vender: «E este preço não estaa sempre em hũ ser, ãtes se muda cõ diuersas taxas dos q̃ gouernão a republica, segundo o tempo, lugar \& maneira de vender: ou com a falta ou auondãça da mercadaria \& do dinheiro, como ho proua bẽ Caietano» (Rodrigo do Porto, Martin de Azpilcueta, 1552: 555). Esta doutrina foi repetida por Martinho de Azpilcueta na edição espanhola do Manual de Confessores (1556): «Y este precio, no esta siempre en vn ser, antes se muda con diuersas tassas de los $\tilde{\mathrm{q}}$ gouiernã la rebublica, con el tiẽpo, lugar y manera de vẽder, o la

de las Indias a nos han venido» (López de Gómara, 1912: 162).

17 "Considerando, por algumas razões, não convir que a revisão do "Manual" se fizesse sé em nome do autor ou só em nome de Navarro e que nela se autonomizasse o que era de um e o que era do outro, concordaram ambos nesta solução: Fr. Rodrigo comunicava a Navarro os seus trabalhos de autor ou compositor e Navarro comunicava a Fr. Rodrigo os trabalhos de reformador, de modo que a obra ficasse comum de ambos, sem possibilidade de qualquer deles reivindicar direitos exclusivos sobre qualquer parte.» (Pereira da Silva, 1975: 373). 
falta o sobra de la mercaderia, y del dinero como lo prueua biẽ Caietano» (Rodrigo do Porto, Azpilcueta Navarro, M. de, 1556: Cap. 23. De los siete pecados mortales, p. 472). Também esta doutrina do preço justo (1552) foi repetida nas ediçãos portugueses do Compendio e sumario de confessores tirado de toda a substancia do Manual $(1567,1569,1571,1579))^{18}$

Aqui devemos notar que até o ano de 1552 Martinho de Azpilcueta não mencionou o dinheiro na sua doutrina de preço justo. $\mathrm{Na}$ sua primeira obra impressa In tres de poenitentia distinctiones posteriores commentarii (1542) Azpilcueta declarou que o preço justo de uma mercadoria baixou ou subiu não só por causa da sua venda mais principalmente pela abundância ou falta de compradores: «Vltroneæ merces vilescunt pro tertia parte. An item causa vendendi. puta, quia ob necessitatem vel abundantia venditur. Qui tandem videtur concludere neque per vendendi modum, neque per vendendi causam iustum diminui precium, sed per copiam emptorum vel penuriam. Quod maxime videtur memorandum \& male per eos servatur, qui nunque emunt, nisi ab iis, qui quærunt emptores sive id necessitate coacti agant, sive alia de causa». (Azpilcueta, 1542: 108) ${ }^{19}$

Na segunda edição do Manual de confessores (1552) os dois autores -Frei Rodrigo e Doutor Navarro- combinaram a dourina de Rodrigo do Porto (1549) com a doutrina de Martinho de Azpilcueta (1542) incluindo a sua nova doutrina do preço justo (muito seme-

18 «E este preço não està sempre em hum ser, antes se muda com diuersas taxas dos que gouernão a republica, segũdo o tempo, lugar \& maneira de vender: ou com a falta ou abastança da mercadaria, \& do dinheiro» (Rodrigo do Porto, 1567, cap. 24, p. 344). No seu Compendio de Manual de Confessores (1586) o Doutor Navarro também repetiu esta doutrina combinada: «Y que este precio no esta siempre en vn ser, antes se muda cõ diuersas tassas de los que gouiernan la republica, con el tiempo, lugar y manera de vender, o la falta, o sobra de la mercaderia, y del dinero.» (Azpilcueta Navarro, 1586: cap. 23, f. 146).

19 «Las mercancías se abaratan por tres factores. Uno, por la causa de su venta, por ejemplo, porque se venden por necesidad, o por su abundancia. De lo cual parece concluirse que no es justo que se disminuya el precio ni por el modo de vender ni por la causa de la venta, sino sólo por la abundancia o escasez de los compradores. Esto debe ser recordado principalmente, y es difícil que lo guarden quienes sólo compran a aquellos que buscan compradores o bien los que actúan obligados por la necesidad, o según alguna otra causa.» (Tradução espanhol da Sra. Professora Ma Idoya Zorroza, veja-se (Afanasyev, 2016, p. 18)). 
lhante à doutrina de Saravia de la Calle) a quantidade de dinheiro (da doutrina de Fr. Rodrigo, 1549), a quantidade dos compradores (da doutrina de Dr. Navarro, 1542), o tempo (da doutrina de Fr. Rodrigo, 1549) e também o lugar, a maneira da venda, a quantidade dos vendedores: «Auisamos porem o que ali não fizemos que pera desfazer por esta rezão contrato, não somente he necessario prouar. Que ao tempo do cõtrato, tanto mais ou tanto menos valia naquella terra segundo o preço comũ: mas ainda, que valia tanto mais ou menos naquelle lugar \& tẽpo \& maneira de vẽder quãdo, onde, \& como se vẽdeo. E ainda o outro pode prouar, aque ho anno, tẽpo \& lugar erão de fome, guerra ou mortes, em que sobelauão vendedores, \& cousas que se vendião daquella qualidade, de que he, aquelle cõprou: e faltauão compradores \& dinheiro: \& rogauão os vẽdedores \& não querião os cõpradores. Polo qual prouado, prouaria que o q̃ elle cõmprou valia muyto menos, do que em outro tẽo, lugar ou maneira de vender, valera, polo acima dito» (Rodrigo do Porto, Martin de Azpilcueta, 1552: 556-557).

Martinho de Azpilcueta repetiu esta nova doutrina combinada do preço justo (1552) nas suas ediçãos espanlholes do Manual de confessores (1553, 1556) ${ }^{20}$ (Rodrigo do Porto, Azpilcueta, 1556: cap. 23 , pp. 472, 475). Mais claramente e mais completamente esta doutrina nova foi apresentada pelo Dr. Navarro no seu Enchiridion sive manuale confessariorum et poenitentium (1573), mas sem a quantidade de dinheiro ${ }^{21}$ (Muñoz de Juana, 1998: 168-176, 177-185).

\footnotetext{
${ }^{20}$ «Auisamos + empreo aquello que alli no hizimos, que para deshazer por esta razon el contrato, no solamente es menester prouar, que al tiempo contrato tanto mas, o tanto menos valia en aquella tierra, segun la comun estimacion: pero aun que valia tanto mas o menos en aquel lugar, y tiempo, y manera de vender quando, donde, y como se vendio. $\mathrm{Y}$ aun el otro puede prouar, que el año, tiempo, y lugar, eran de hambre, guerra o mortãdad, en que sobrauan vendedores, y cosas vendibles, de aquella qualidad, de que es la que el compro: y faltauan compradores, y dineros: y rogauã los vendedores, y rehuyan los compradores. Por lo qual prouado, prouaria q̃ lo que el compro, valia mucho menos de lo que en otro tiempo, lugar, o manera de vender valiera, por lo dicho». (Rodrigo do Porto, Azpilcueta Navarro, M. de, 1556: Cap. 23. De los siete pecados mortales, p. 475)

${ }^{21}$ «Secundo quod pretium iustium rei (cuius notitia maxime necessaria est plurimis utriusque iuris, \& aliquot Theologiæ locis intelligendis ) est pretium pecuniarium quo communiter æstimatur res ualere tunc, attenta illius intrinseca bonitate \& uendentis utilitate, loco, tempore, \& copia, uel defectu rerum illius generis,
} 
Portanto, podemos ver que Martinho de Azpilcueta herdou a doutrina do preço justo de Fr. Rodrigo do Porto (1549) como a base da sua $(1556,1573)$ e com grande probabilidade podemos supor que a doutrina do preço justo de Fr. Rodrigo (1549) ajudou Azpilcueta a conhecer teoricamente de alguma forma a relação direta entre a quantidade de dinheiro e os preços das mercadorias na Península Ibérica.

A outra influência da doutrina do preço justo de Fr. Rodrigo do Porto (1549) no pensamento economico do Dr. Martinho de Azpilcueta é a possibilidade lícita de vender o pão espanhol por mais do que o preço justo estabelecido pelos editais dos Reis Católicos em 1503 e do Imperador em 1539, mas vender tão caro como a justiça natural permite. Muitos riquezas tinham vindo do Novo Mundo para a Espanha e, portanto, a demanda para o pão aumentou em 1503-1552, mas a taxa mudou um pouco e apenas uma vez; por isso, a produção de pão em Espanha tinha caído e o trigo foi importado dos países vizinhos e vendeu muito mais caro do que o trigo doméstico. Esta taxa era injusta e por isso não obrigava, diziam Fr. Rodrigo e Doutor Navarro: «Dissemos (taxa justa) porque a injusta não obriga segundo a mente đ todos. E se ella he injusta ou não, por se dar hũa a todos los trigos \& grãos, maos bõs, \& muy bõs, nuovos \& velhos, saãos \& corruptos: de hũa terra onde ha muyto, \& doutra onde ha pouco: E do que nace onde se vende, \& do que se traz de longe, anda que seja do reyno, sem dar nada mays por os alugueres, permittindo que ho đ fora do reyno se venda como cada hũ poder, \& muyto mais caro que ho do reyno, sendo muyto pior: E se esta taxa desigual daa material de peccar, \& occasião de muytos peccados mortaes, se temos q̃ a trãsgressam della obriga a mortal, como dizem os sobre ditos doutores: remetemolo aos authores da ley, \& ao q̃ em outra parte dizemos: parecendonos por agora (polo acima dito) $\tilde{\mathrm{q}}$ a tẽção do autor da ley, q̃ põe pena, cõtra quem vẽde mais de a tanto, não he de obrigar a peccado mortal. † Ainda que o trangressor della peccaria mortalmente, se vendesse por mais da justa notauelmente: posto que ho vendesse por menos da taxa: Como soem vender algũs o pão ou vinho corrupto, que val pouco

\& emptorum, \& uenditorum earum, \& modo uendendi eam, statutum a Gubernatore loci, uel domino rei.» (Azpilcueta, 1573: cap. xiii, f. 361). 
mais de nada: Porque quebrantão a ley natural \& divina. E que ao contrairo, não peccarião mortalmente, se ho vendessem polo preço que diãte Deos fosse justo, ainda que excedessem a taxa tãto, quanto a justiça natural permitte. $\rangle^{22}$ (Rodrigo do Porto, Martin de Azpilcueta, 1552: 559-560).

Em nossa opinião, estas duas conclusões importantes na segunda edição do Manual de Confessores e Penitentes (1552) - (1) o fator de dinheiro como um dos dois principais para determinar o preço justo (a doutrina de Fr. Rodrigo (1549) que foi repetida em 1552) e (2) a possibilidade de vender uma coisa necessária, como o pão, mais caro que o preço justo fixado pela lei (a doutrina combinada de Fr. Rodrigo e Dr. Navarro) - desempenharam o papel importante na formação da Teoria Quantitativa do Dinheiro de Azpilcueta que foi descoberta no seu Comentario resolutorio de Cambios em 1556.

Devemos notar que em meados do século XVI o obstáculo para o descobrimento da Teoria Quantitativa do Dinheiro passa por muitos professores (por exemplo, Nicolaus Copérnicus ${ }^{23}$ e Domin-

${ }^{22}$ «Diximos † (tassa justa) porq̃ la injusta no obliga, segun la mente de todos. Y si ella es injusta, o no, por se dar vna a todos los trigos y granos malos, buenos, y muy buenos, nueuos, y añejos, sanos, y corrõpidos, de vna tierra do ay mucho, y de otra, do ay poco: del q̃ nace do se vende, del q̃ se trae de lexos, aun q̃ se trayga del reyno, sin dar nada mas por los alquileres: permitiendo, $\tilde{\mathrm{q}}$ lo de fuera del reyno se venda como se pudiere, y mucho mas caro, que el del reyno, siendo mucho peor. Y si esta tassa desygual da materia de pecar, y ocasiõ de vna sin fin de pecados mortales (si tenemos que la transgressiõ della obliga a mortal, como dizẽ los sobre dichos doctores) remitimoslo a los legisladores, y a lo que en otra parte dezimos: pareciẽdo nos por agora (por lo arriba dicho) que la intencion del legislador, q̃ pone pena cõtra quien mas de a tãto vẽde, no es de obligar a pecado mortal. Aun + ã el transgressor della pecaria mortalmente, si vendiesse por mas del justo valor notablemente: aun q̃ lo vendiesse a menos de la tassa: como suelen vender algunos el pan, o vino corrupto, que vale poco mas de nada. Porque quebrantan la ley natural, y diuina. Y que al reues, no pecarian mortalmente, si lo vendiessen al precio, que delante Dios fuesse justo, aun que excediesse la tassa, tanto quanto la justicia natural permite» (Rodrigo do Porto, Azpilcueta Navarro, M. de, 1556: Cap. 23. De los siete pecados mortales, pp. 476-477).

${ }^{23}$ No seu manuscrito Monete cudende ratio (1526) Copernicus escreve: «Est autem moneta aurum vel argentum signatum, qua pretia emptibiliurn vendibiliumque rerum numerantur secundum cujusvis reipublice vel gubernantis ipsum institutum. Est ergo moneta tanquam mensura quædam communis æstimationum. Oportet autem id quod mensura esse debet firmum semper ac statum servare modum. Alioquin necesse est confundi ordinationem reipublice, ementes quoque et vendentes multipliciter defraudari, quemadmodum si ulna, modius, pondusve certam 
go de Soto) continuarem a considerar que o dinheiro não era uma mercadoria, que o dinheiro era apenas um meio de troca e uma medida dos valores das mercadorias e, portanto, o valor do dinheiro em referencia aos bens (para servir como a medida estável) devia ser fixado pela lei, por isso não era licito vender o dinheiro por mais ou menos da taxa fixada pela lei. Este problema foi resolvido pelo doutor Martinho de Azpilcueta Navarro em 1556 no seu Comentario resolutorio de cambios ${ }^{24}$.

VII

\section{A TEORIA QUANTITATIVA DO DINHEIRO DE MARTINHO DE AZPILCUETA (1556)}

O doutor Azpilcueta provou que o dinheiro foi uma mercadoria e, portanto, de acordo com Santo Tomas e com a sua doutrina de $l u-$ crum cessans, foi justo para os vendedores de dinheiro (os compradores dos bens) vender a moeda por mais ou menos da taxa fixada pela lei ${ }^{25}$.

Então o valor do dinheiro pode baixar ou subir do mesmo modo que o valor das outras coisas vendáveis de acordo com a sua abundância ou sua falta: «Lo xx dezimos † que por el septimo respecto

quantitatem non servet» (Copernicus, 1864: p. 48). Tradução em francês: «L'or ou l'argent marqués d'une empreinte, constituent la monnaie servant à déterminer le prix des choses qui s'achètent et qui se vendent, selon les lois établies par l'Etat ou le prince. La monnaie est donc en quelque sorte une mesure commune d'estimation des valeurs; mais cette mesure doit toujours être fixe et conforme à la règle établie. Autrement, il y aurait, de toute nécessité, désordre dans l'Etat: acheteurs et vendeurs seraient à tout moment trompés, comme si l'aune, le boisseau ou le poids ne conservaient point une quotité certaine» (Copernicus, 1864: 49).

${ }^{24}$ Veja-se os argumentos de Domingo de Soto, os argumentos e contra-argumentos de Martinho de Azpilcueta em mais detalhes em (Muñoz de Juana, 1998: 327-330).

25 «Porende + respondemos nueuamente concediendo, que el dinero esta tassado para vn effecto, y no para otro: Esta tassado para effecto de compeler al que algo vende, o se le deue, que lo tome por aquel precio, y que no pueda ser compelido a tomarlo por mas: pero no esta tassado para effecto, que quien lo tiene, no puede lleuar menos por el, si quiere, ni para que no pueda lleuar mas, si alguna comodidad particular le resulta. ... Porq̃ el vendedor no puede vender la cosa mas cara, por el prouecho particular, que dello viene al comprador: aunq̃ si, por el que el pierde en venderlo, segun S. Thomas y Soto» (Azpilcueta, 1556: §58, p. 88-89). 
que haze subir, o baxar el dinero, que es de auer gran falta, y necessidad, o copia del, vale mas donde, o quendo ay gran falta del, que donde ay abũdancia: como lo tienen Calderino, Laurencio Rodulpho, y Siluestro, con quien Caietano, y Soto concuerdan. Por cuya opinion, haze lo primero: Que este es el comun concepto de quasi todos los buenos y malos de toda la Christiandad, y por esso parece boz de Dios, y de la naturaleza. Lo segũdo, y muy fuerte, que todas las mercaderias encarecen por la mucha necessidad que ay, $y$ poca quantidad dellas: y el dinero, en quanto es cosa vẽdible, trocable, o comutable por otro contrato, es mercaderia, por lo susodicho, luego tambiẽ el se encarecera con la mucha necessidad y poca quãtidad del. Lo tercero, que (siẽdo lo al ygual) en las tierras, do ay gran falta de dinero, todas las otras cosas vendibles, y aun las manos y trabajos delos hombres se dan por menos dinero, que do ay abundancia del, como por la experiencia se vee, que en Francia, do ay menos dinero, q̃ en España, valen mucho menos el pan, vino, paños, manos, y trabajos de hombres: y aun en España, el tiẽpo, que auia menos dinero, por mucho menos se dauan las cosas vendibles, las manos y trabajos de los hombres, que despues, que las Indias descubiertas la cubrieron de oro y plata. La causa de lo qual es, que el dinero vale mas donde, y quando ay falta del, que donde, y quando ay abundancia, y lo que algunos dizen: que la falta del dinero abate lo al, nace, de que su sobrada subida haze parecer lo al mas baxo, como vn hõbre baxo, cabe vn muy alto parece menor, que cabe su ygual» (Azpilcueta, 1556: § 52, pp. 84-85).

\section{VIII \\ A PRIMEIRA FORMALIZAÇÃO MATEMÁTICA \\ DA DOUTRINA DO PREÇO JUSTO DE FR. RODRIGO DO PORTO}

Mais de dois séculos se passaram desde a publicação do Manual de Confessores de Frei Rodrigo do Porto e dos Comentarios resolutorios do Doutor Martinho de Azpilcueta Navarro, quase ninguém se lembrava a sua grande contribuição para a teoria monetária e para a teoria do preço justo, mas as suas idéias pioneras e a sua Teoria Quantitativa do Dinheiro continuaram a viver nas mentes dos ho- 
mens. Em 1771 o major-general do Exército russo ${ }^{26}$, o galês Henry Humphrey Evans Lloyd (1718-1783) na sua obra intitulada An essay on the theory of money formalizou em termos matemáticos a doutrina do preço descoberta por Fr. Rodrigo do Porto ${ }^{27}$ : «Though the price of any commodity is in fact in a compound ratio, direct as the quantity of circulation, and inverse of that of merchandize, yet it may be simplified, and reduced to the expression we have adopted, because it is the same thing, whether you increase the circulation, or diminish the quantity of merchandize, or that you increase this, and diminish that; For example, Let the circulation be expressed by $C$, and the quantity of merchandize by $M$, and the price or propotrion between them by $p$; we shall have the following equation, $C / M=p . »\left(\right.$ Lloyd, 1771, p. 83-84) ${ }^{28}$. Por sua vez, a equação do general Lloyd foi o protótipo e a base para a equação de troca (trocas) na macroeconomia moderna $M V=P T^{29}$.

${ }^{26}$ O general Lloyd servia no exército russo em 1770s. A imperatriz Catarina a Grande gostava dele e estimava muito. O Marquês de Mesmon nos descreveu uma audiência de Lloyd com a imperatriz: «L'Impératrice voulut un jour diner chez lui, "ah, Madame! s'écria le Général en allant la recevoir, Votre Majesté me perd, \& me met hors d'état de pouvoir la servir; - pourquoi donc Lloyd, dit la Czarine.- Madame, l'envie ne me pardonnera jamais l'honneur dont Votre Majesté me comble aujourd'hui"» (Romance, marquis de Mesmon, 1784: xxvi).

${ }^{27}$ Sobre a equação da «Teoria Quantitativa do Dinheiro» do general Lloyd veja-se (Theocharis, 1961).

28 «Money which call Univerfal Merchanadife, becaufe it can, all civilized nations, be exchanged for every fpecies of productions, fhould have the following qualities Ift. It Thould be rare, and uncommon that fmall quantity of it may ferve as an equivalent, to much greater of any other production; and be, eafily, tranfported from one country to an other. $2 \mathrm{~d}$, That it fhould not wear or be eafily counterfeited. $3 \mathrm{~d}$, That it be divifible, in order to facilitate its ufe, for this reafon metals are preferred to precious ftones, which cannot be divided into proportionable parts. The advantages, which focieties derived from the ufe of money, induced them to augment its courfe; for which reafon they introduced the ufe of Banks, public notes, \&e. The neceffities of the ftate, as well as of individuals, gave birth to borrowing and lending, which neceffarily introduced the general ufe of public and private notes; and when their credit is good, are received as an equivalent for real money, and therefore produce the fame effect having the fame value, where such private and public notes are eflablifhed: I fhall call the one and the other by the general name of Univerfal merchandize or general circulation» (Lloyd, 1771: pp. viii-x).

${ }^{29} M$ é a quantidade de moeda (a oferta monetária), $V$ é a velocidade de circulação da moeda (dinheiro), $P$ é o nível geral de preços, $T$ é o volume de transações (calculado a preços comparáveis). A Teoria Quantitativa do Dinheiro (Moeda) diz que se $V$ e $T$ 
IX

\section{CONCLUSÕES}

Assim, podemos concluir:

a) Há o origem ibérico e, em particular, português da formação da Teoria Quantitativa do Dinheiro. Fr. Rodrigo do Porto na primeira edição do Manual de confessores e penitentes (1549) teoricamente indicou uma relação direta entre a quantidade de dinheiro e o preço da mercadoria. Em outras palavras, a grande contribuição de Fr. Rodrigo do Porto para a formação da Teoria Quantitativa do Dinheiro é que no seu Manual de confessores (1549) o franciscano português indicou dois principais fatores que determinaram o preço justo de uma mercadoria: a quantidade de dinheiro e a quantidade desta mercadoria.

b) A inspiração possível do Manual de confessores (1549) de Fr. Rodrigo do Porto para a formação da teoria do preço justo e teoria quantitativa de doutor Martinho de Azpilcueta Navarro, a nosso ver, é que o Dr. Navarro incluiu a quantidade de dinheiro na sua doutrina do preço justo (1556).

c) Além disso, Martinho de Azpilcueta Navarro herdou a doutrina do preço justo de Fr. Rodrigo como a base da sua doutrina do preço justo nas ediçãos posteriores do Manual de Confessores $(1552,1553,1556,1573)$ e provavelmente podemos supor que a doutrina do preço justo de Fr. Rodrigo ajudou Azpilcueta a conhecer teoricamente de alguma forma a relação direta entre a quantidade de dinheiro e os preços das mercadorias na Península Ibérica.

d) Na segunda edição do Manual de confessores (1552) os dois autores Fr. Rodrigo e Dr. Navarro indicam a possibilidade licita de venda de pão acima da taxa fixada pela lei quando a demanda aumenta. A demanda aumentou principalmente por causa da importação dos metais preciosos.

são constantes ou estáveles, o nível geral de preços é determinado pela quantidade da moeda no país e está na proporção direta desta quantidade: $P=M \cdot(V / T)$. Em outras palavras, o valor da moeda $1 / P$ é determinado pela sua quantidade e está na proporção inversa desta quantidade $1 / P=1 / M \cdot(T / V)$. 
e) A doutrina pionera do preço justo descoberta por Fr. Rodrigo do Porto em 1549 tinha sido apresentada e formalizada em termos matemáticos por um dos pensadores da Escola de Milano o major-general Henry Humphrey Evans Lloyd (1718-1783) no seu livro An essay on the theory of money (1771). Enquanto isso, a equação do general Lloyd foi o protótipo e a base da equação de troca (trocas) na macroeconomia moderna.

f) Além disso, investigamos a doutrina sobre o preço justo de Frei Rodrigo do Porto (1549) em mais detalhes no nosso artigo castelhano: Afanasyev Anton A., «La doctrina sobre el precio justo en el Manual de Confessores e Penitentes (1549) de Fr. Rodrigo do Porto, OFM» (Cauriensia, 2016, Vol. XI).

\section{BIBLIOGRAFIA}

\section{Fontes primárias}

Azpilcueta Navarrus, M. (1542): Martini ab Azpilcueta Nauarri iuriscõsulti in tres de poenitẽtia distinctiones posteriores commentarii. Conimbricę: ex officina Iohannis Alvari et Iohannis Barrerii, M.D.XLII.

- (1556): «Comentario resolutorio de Cambios, sobre el principio del capitulo final de vsuris», en Martin de Azpilcueta Navarro, Comentario resolutorio de vsuras, sobre el cap. j. de la question. iij. de la. xiiij causa, compuesto por el Doctor Martin de Azpilcueta Nauarro. Dirigido con otros quatro sobre el principio del cap. fin. De vsur. Y el cap. fin. De symo. Y el cap. Non inferenda. xxiij. quest. iij. Y el cap. fin. xiiij. questi. final. Al muy alto, y muy poderoso Señor Don Carlos principe de Castilla, y otros muchos y muy grandes reynos nuestro Señor. Para mayor declaracion de lo que ha tratado en su Manual de Confessores. Impresso en Salamanca: en casa de Andrea de Portonarijs, 1556 (12 augosto). P. 48-104.

- (1586): Compendio del Manual de Confessores, y Penitentes, del Doctor Don Martin de Azpilcueta Nauarro, de la Sacra Penitenciana de Roma. En Valladolid: en casa de Diego Fernandez de Cordoua 
Impressor de Su Magestad por Antonio Suchet, Año de M.D.LXXXVI.

Copernicus, N. (1864): «Monete cudende ratio per Nicolaum», en Wolowski, M.L. (éd.), Traictie de la premiere invention des monnoies de Nicole Oresme et Traite de la monnoie de Copernic. Paris: Librairie de Guillaumin et $C^{\mathrm{IE}}$, 48-78.

- (1924): «Tractatus de monetis», en Dmochowsky, J. (éd.), Mikołaja Kopernika rozprawy o monecie i inne pisma economiczne. Warszawa - Kraków - Lublin - Łódź - Poznań - Wilno - Zakopane: Geberthner i Wolff, 1.

De Vio Caietanus T. (1506): Tractatus de Cãbijs fratris Thome Caietani ordinis Predicatorum $\mathcal{E}$ sacre theologie professoris ad Uenerabile predicatorem \& priorem Brixie fratrem Andream brixiẽsem eiusdẽ ordis (Mediolani: ĩ ouẽtum s. Marie grarũ, Anno salutis 1499. Die 9. Decembris), in De Vio Th., Reuerẽdissimi in Christo fratris Thome de Uio Caietani Artium \& Sacre Theologie professoris ordinis predicator In Romana curia Procuratoris dignissimi Cõmentaria subtilissima super Tractatum de Ente \& Essentia Sãctissimi doctoris Thome de Aquino eiusdem ordinis. Item super libros Posteriorum Aristotelis $\mathcal{E}$ Predicamenta nouiter per prefatum magistruz Thomam Reuisa: Et quibus addite sunt quedam appostille multum utilissime quas alia non habent. Ite est adiüct' tractat' de analogia no um pulcherrim'. Item mirabilis question de Subiecto philosophie. Item Tractatus de Cambijs per uendem Magistrum Thomam nouiter compositus. Item tabule abundantissimeque omnia habent que in toto opere tractantur. Cum Gratia et Priuilegio. - Venetijs: per Simone de Luere, M.D.VI. (die xiii octobris) - F. 51-54.

- (1519): In secundam secunde sanctissimi ac preclarissimi doctoris Thome Aquinatis ordinis Predicatorum Cõmentaria celeberrima Re-

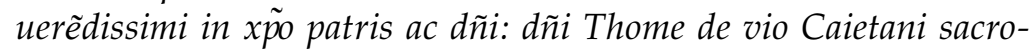
sancte Romane ecclecie: tituli sancti Sixti: presoyteri Cardinalis sacre theologie professoris eminentissimi quõdam Predicator ordinis generalis magistri: correcta iãdudũ adamissim ab eximio doctore theologo magistro Petro de Flouimagio regente Lonuentus Parisiensis eiusdem ordinis Predicatorum clarissimo. Parisiis: venundantur a Claudio Cheuallon, 1519 (17 die maii).

LAS CASAs, B. (1552): Entre los remedios q̃ dõ fray Bartolome de las casas; obispo d la ciudad real de Chiapa: refirio por mandado del Em- 
perador rey nro señor: en los ayutamiẽtos q̃ mãdo hazer su magestad de perlados y letrados y personas grãdes en Valladolid el año de mill $\mathcal{E}$ quiniẽtos y quarẽta y dos: para reformaciõ de las Indias. En la muy noble y opulentissima y muy leal ciudad de Seuilla: en las casas de Jacome Crõberger, 1552 (17 de Agosto).

LeVILLIER, R. (ed.) (1921): Gobernantes del Perú, cartas y papeles, siglo XVI. Madrid: Sucesores de Rivadeneyra. Tomo I.

[LLOYD, H.] (1771). An essay on the theory of money. London: printed for J. Almon, opposite Burlington-House, Piccadilly.

LóPeZ DE Gómara, F. (1912). Annals of the Emperor Charles V (Spanish text with English translation) / Edited, with an introduction and notes, by R.B. Merriman. Oxford: Clarendon Press.

[Rodrigo Do PORTO] (1549): Manual de confessores, E penitẽtes, em ho qual breue $\mathcal{E}$ particular, $\mathcal{E}$ muy uerdadeyramente se decidem, $\mathcal{E}$ declarã quasi todas as duuidas, $\mathcal{E}$ casos, que nas confissões soẽ occorrer acerca dos peccados, absoluições, restituyções, E encuras: Composto por hũ religioso da ordem de sam Francisco da prouincia da piedade. Foy vista, $\mathcal{E}$ examinada, $\mathcal{E}$ aprouada a presẽte obra por o Doutor Nauarro, cathedratico de prima ẽ canones na Uniuersidade de Coimbra. Por comissam do Infante Cardeal inquisidor mayor nestes Reynos. Na muyto nobre \& leal cidade de Coimbra: por Ioã da barreyra \& Ioã de aluares emprimidores da mesma vniuersidade, M.D.XLIX (27 de Iulho).

- $\mathcal{E}$ Azpilcueta Navarro, M. (1552): Manual de confessores $\mathcal{E}$ penitentes, que clara \& breuemente contẽ a vniuersal \& particular decisão, de quasi todas as duuidas q̃ nas cõfissões sõe occorrer dos peccados, absoluições, restituições, cẽsuras $\mathcal{E}$ irregularidades: Cõposto antes por hũ religioso da ordem de S. Francisco da prouincia da Piedade: E visto $\mathcal{E}$ em algũs passos declarado polo muy famoso Doutor Martim de Azpilcueta Nauarro, cathedratico iubilado de Prima em Canones na vniuersidade de Coimbra. E despois cõ summo cuidado, diligẽcia $\mathcal{E}$ estudo, tã reformado $\mathcal{E}$ acrecẽtado polo mesmo Author $\mathcal{E}$ o dito Doutor em materias, sentenças, allegações $\mathcal{E}$ estilo q pode parecer outro, com Reportorio copioso no cabo. In inclyta Conimbrica: Ioannes Barrerius et Ioannes Aluarez excudebãt, anno a Cristo nato M.D.LII (die Diua Luciae Sacro 13 Dez.).

- (1556): Manval de confessores y penitentes, que clara y brevemente contiene, la vniversal y particylar decision de quasi todas las dodas, 
que en las confessiones suelen ocurrir de los pecados, absoluciones, restituciones, centuras, E irregularidades. Compuesto por el Doctor Martin de Azpilcueta Nauarro Cathedratico Iubilado de Prima en Canones, por la orden de un pequeño, que en Portugues hizo un padre pio de la pijssima Prouincia de la piedad. Acrescentado agora por el mesmo Doctor con las decisions de muchas dudas, q despues de la otra edicion le han embiado. Las vnas de las van insertas so esta señal * las otras en cinco Comentarios de Vsuras, Cambios, Symonia mental, Defension de proximo, De hurto notable, y irregularidad. Con su reportorio copiosissimo. Con priuilegio Apostolico, Real de Castilla, Aragon, y Portugal. - Impresso en Salamanca: en casa de Andrea de Portonarijs, Impressor de la S.C. Magestad, 1556 (10 de Iulio).

- (1567). Compendio e sumario de confessores tirado de toda a substancia do Manual. Copilado \& abreuiado por hũ religioso frade Menor da ordẽ de S. Francisco da prouincia da Piedade. Acrecẽtarãselhe em os lugares cõueniẽtes as cousas mais cõmũas q̃ se ordenarã em o scto Cõcilio Tridẽti. Impresso em Coimbra: por Antonio de Maris Impressor do Arcebispo de Braga Primas \&c., 1567 (o derradeyro de Setembro).

Saravia de la Calle Beronense (1547): Instrucion de mercaderes muy prouechosa. En la cual se enseña como deuen los mercaderes tractar y de que manera se han de euitar las vsuras de todos los tractos de ventas $\mathcal{E}$ compas. Assi a lo contado como a lo adelantado: y aloñado y delas compras del censo al quitar: y tractos de compañia: y otros muchos contractos. Particularmente se habia del tracto de las lanas. Tambien ay otro tractado de cambios. En el qual se tracta de los cambios licitos y repronados. Nueuam te cõpuesto por el doctor Sarauia de la calle Beronense. En la muy noble villa de Medina del campo: por Pedro de Castro impressor de Libros, MCXLVII (3 Enero).

Thoma Aquinatis, Ptolomaeus de Lucca (1509): Sanctissimi doctoris, Diui scilicet Thome Aquinatis: ordinis fratrum prædicatorum: libri quattuor de regimine principum ad regem Cypri. Itẽ Epistola eiusdeq3 De regimine iud orum vẽditiõe officiorum ( $q^{\prime}$ videlicet nõ est expediẽs) de exactiõibus in subditos nõ faciedis. Et institutis restitu dis ad ducissam Brabantix. - Parisiis: Venundantur ab Ioanne paruo sub Leone argenteo parisiis in via ad diuum Iacobum, 1509. 


\section{Estudos}

Afanasyev, Anton A. (2016): La Escuela de Salamanca del siglo Xvi: algunas contribuciones a la ciencia económica, Revista Empresa y Humanismo, vol. XIX, No. 1, pp. 7-30.

- (2000): [Афанасьев Антон Александрович (2000)]: Зависимость объема бартерных сделок от изменения количества денег в обращении и темпа инфляиии [A dependência do volume de operações de troca na quantidade de moeda em circulação e da taxa de inflação]/ Tese do candidato das ciências económicas apresentada no Instituto Central de Economia e Matemática da Academia Russa de Ciências. Moscou. (http://www.cemi.rssi.ru/publication/e-publishing/afanasiev/afanas-diss.pdf)

- (2004) (Афанасьев, А. А.): «Экономическая мысль в Испании XVI века-саламанкская школа», в журн. Экономика и математические методы, 2004 (т. 40, 4), с. 26-58 («O pensamento econômico na Espanha do século XVI: a Escola de Salamanca», Economia e métodos matemáticos, 40, 4, 26-58).

- (2013) [Афанасьев Антон Александрович (2013)]. Моделирование процессов денежного обращения в хозяйстве с газовой отраслью, [Modelagem de processos de circulação de dinheiro na economia com a indústria do gás] / Tese do doctor das ciências económicas apresentada no Instituto Central de Economia e Matemática da Academia Russa de Ciências. Moscou. (http://www.cemi.rssi. $\mathrm{ru} /$ staff/Thesis/index.php?ELEMENT_ID=7182)

BAIÃO, A. (1919): Episódios dramáticos da inquisição portuguesa. Vol. I. Homens de letras e de sciência por ela condenados. Porto: Renascença Portuguesa. 332 p.

Barbosa Machado, D. (1741): Bibliotheca Lusitana Historica, Critica, e Cronologica. Na qual se comprehende a noticia dos Autores Portuguezes, e das Obras, que compuzeraõ desde o tempo da promulgaçaõ da Ley da Graça até o tempo presente. Por Diogo Barbosa Machado. Lisboa Occidental: na Officina de Antonio Isidoro da Fonseca. Tomo I.

- (1752): Bibliotheca Lusitana Historica, Critica, e Cronologica. Na qual se comprehende a noticia dos Autores Portuguezes, e das Obras, que compuzeraõ desde o tempo da promulgaçaõ da Ley da Graça até o tempo presente. Por Diogo Barbosa Machado. Lisboa: na Officina de Ignacio Rodrigues. Tomo III. 
- e Sousa Farinha, B. J. (1786): Bibliotheca luzitana escolhida. Lisboa: na officina de Antonio Gomes.

- (1787): Summario da Bibliotheca Luzitana. Lisboa: na Of. da Academia Real das Scienc. Tomo III.

Costa de MACEDO, A. J. (1799): Catalogo dos livros, que se haõ de ler para a continuaçaõ do Diccionario da Lingua Portugueza mandado publicar pela Academia Real das Sciencias de Lisboa. Lisboa: na Typographia da mesma Academia.

CARdoso J.L. (coord.) (2001): Dicionário Histórico de Economistas Portugueses. Lisboa: Temas e Debates.

Diccionario Da Lingoa Portugueza publucado pela Academia Real DAS SCIENCIAS DE LisBOA. Tomo I. A. Lisboa: na officina da mesma Academia, 1793.

Grice-Hutchinson, M. E. H. (1952): The School of Salamanca. Readings in Spanish Monetary Theory 1544-1605, Oxford: Clarendon Press.

Muñoz de JuAna, R. (1998): Moral y economía en la obra de Martín de Azpilcueta: Tesis doctoral presentada en la Facultad de Teología de la Universidad de Navarra. Pamplona: Ediciones Universidad de Navarra, S.A.

Monforte, Manoel (1751): Chronica da Provincia da Piedade. Lisboa: na officina de Miguel Manescal da Costa.

Popescu, O. (1984): Orígenes hispanoamericanos de la teoría cuantitativa. Buenos Aires: Facultad de Ciencias Sociales y Económicas de la Pontificia Universidad Católica Argentina Santa María de los Buenos Aires.

Romance, MARQuis de Mesmon, G.-H. (1784): Précis sur la vie et le caractere de Henri Lloyd, in Henry Lloyd, Introduction à l'Histoire de la guerre en Allemagne en M.DCC.LVI, entre le Roi de Prusse et l'Impératrice Reine avec ses Alliés. Ou Mémoires militaires et politiques du général Lloyd / Traduit \& augmentés de Notes \& d'un Précis sur la vie \& le caractère de ce Général. Par un Officier François [G.-H. de Romance, marquis de Mesmon]. Londres et se trouve a Bruxelles: chez A.F. Pion, Imprimeur - Libraire, rue de l'Imperatrice, $\mathrm{i}-\mathrm{xxx}$.

Pereira da Silva, AntónIo (1975). «A primeira suma portuguesa de teologia moral e sua relação com o "Manual" de Navarro", Didaskalia, vol. V, fasc. 2, 355-403. 
Rebello da Costa, A. (1789): Descripção topografica, e historica da cidade do Porto. Porto: na Officina de Antonio Alvares Ribeiro.

TheOcharis, R. D. (1961): Early Developments in Mathematical Economics. Published: New York: St Martin's Press.

\author{
ILUSTRAÇÃO 1 \\ A FOLHA DE ROSTO
}

DO MANUAL DE CONFESSORES E PENITENTES

DE FR. RODRIGO DO PORTO (COIMBRA, 1549)

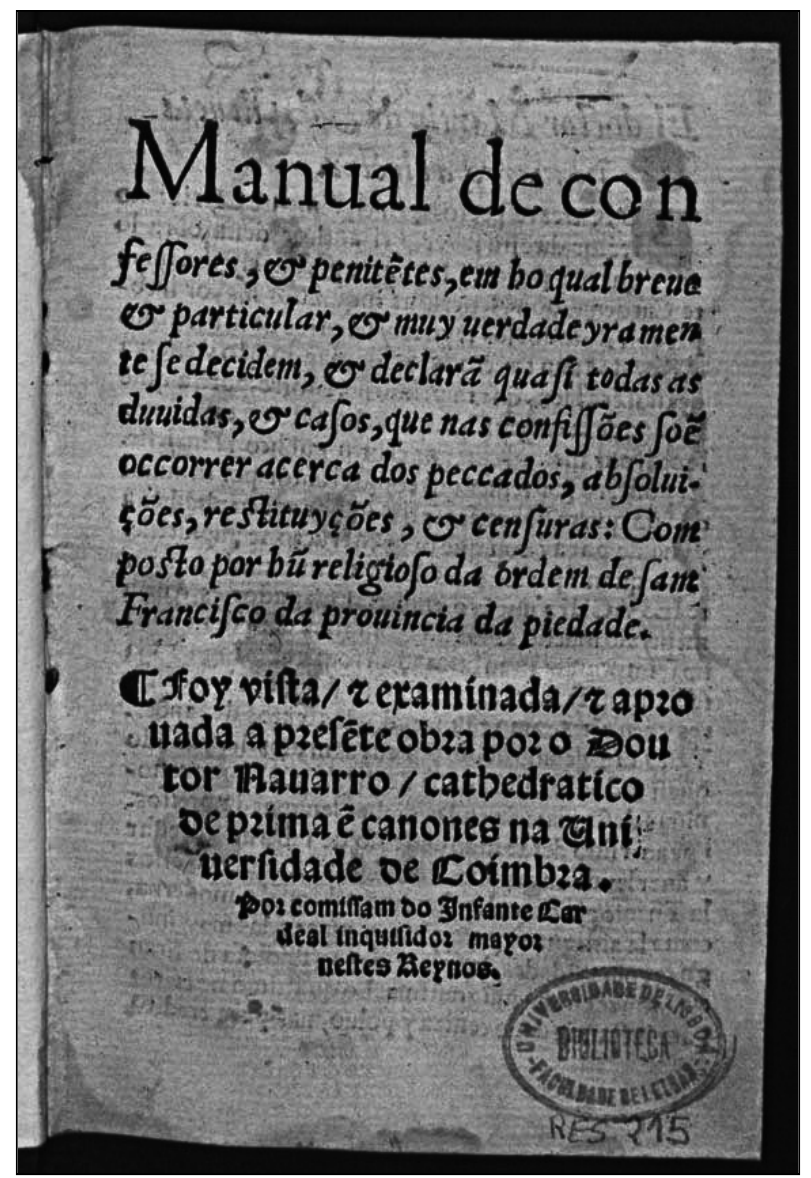

Fonte: Biblioteca Nacional de Portugal 


\author{
ILUSTRAÇÃO 2 \\ A FOLHA DO MANUAL DE CONFESSORES E PENITENTES \\ DE FR. RODRIGO DO PORTO \\ COM AS FONTES DA TEORIA QUANTITATIVA DO DINHEIRO \\ (COIMBRA, 1549)
}

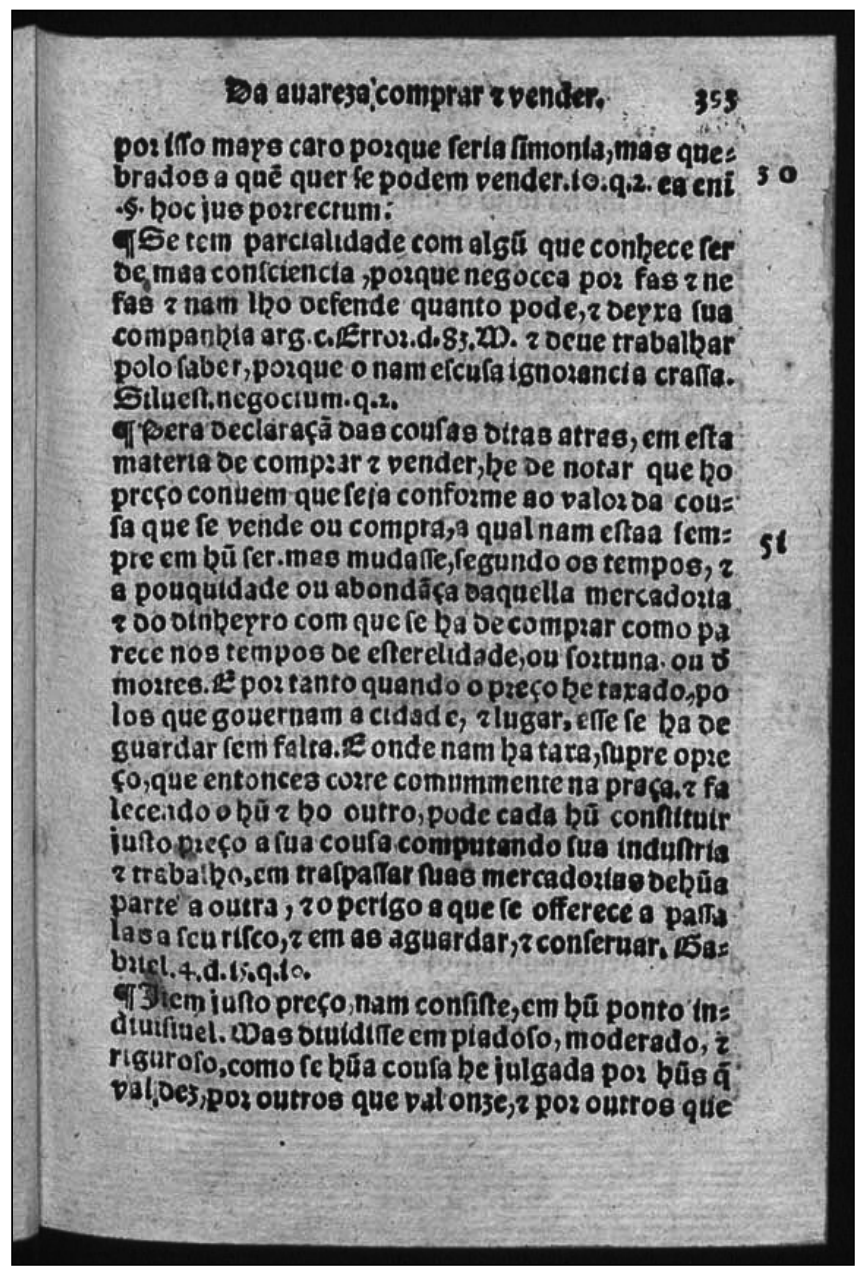

Fonte: Biblioteca Nacional de Portugal 